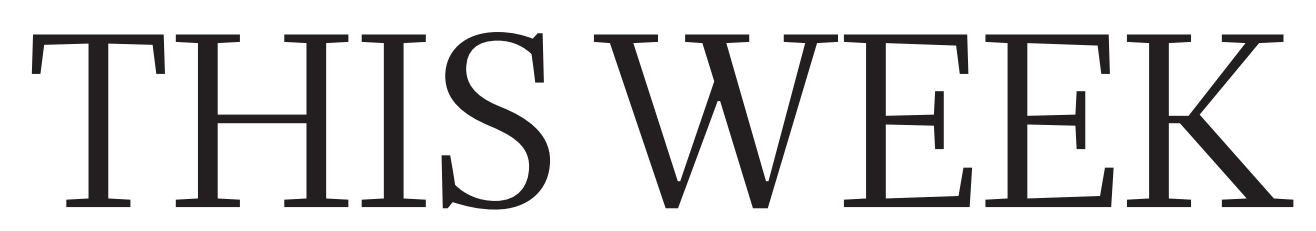

EDITORIALS
CLIMATE Berkeley study generates more heat than light p.428
WORLD VIEW The true challenge of California's clean-energy pledge $\mathbf{p} . \mathbf{4 2 9}$
BIRD BRAINS Tool use not just for the best and brightest $\mathbf{p . 4 3 1}$

\title{
A priceless resource
}

\section{The key to treatments for autism and schizophrenia could lie in the brains of recently deceased children. To make advances, researchers need access to an international bank of donated material.}

$\mathrm{F}$ ew subjects in modern science are as emotive as research on the brains of recently deceased children. The pay-off may seem vague - progress towards understanding, and perhaps treating, neurological conditions including autism and schizophrenia. The difficulties, however, are clearer — the brains must be donated by grieving parents who have just lost a child in sudden and sometimes violent circumstances.

So it is easy to understand the reluctance of individual scientists, institutions and funding agencies to press too vocally for access to more brains from newborns, infants and older children, as well as for fetal brains obtained after abortion. Still, as a News Feature on page 442 shows, some patient groups in the United States are raising their voices. These groups deserve support. Moreover, they need scientific organizations in the United States and abroad to endorse and work towards a more ambitious goal: an international tissue bank holding perhaps tens of thousands of brains from young children and human fetuses around the world. Nature today pledges its support for such a bank.

The case for such a facility comes down to the growing number of scientists who wish to study brains from these early stages of development. Biological technologies now allow the extraction of a wealth of information about neurological diseases caused by faulty brain development. Neurodevelopmental conditions such as autism, schizophrenia and bipolar disorder are a huge societal burden, yet there are few effective treatments for them. Schizophrenia alone costs the United States tens of billions of dollars each year.

Many scientists working on these diseases have no access to young brain tissue. An informal survey of existing brain banks shows that they hold tissue from barely 1,300 brains collected from fetuses, young children and teenagers.

How can the supply to science of such sensitive material - the very seat of a child's personality - be increased on an international scale? The supply shortage is partly down to logistical problems. But these have been solved by some adult brain banks and, in principle, the logistics are no different when it comes to children.

The largest obstacle - real or perceived - remains the sensitivity of the subject and the difficulty of raising it with parents. Ultimately, this must be confronted, and discussions in the United States are being led by autism advocacy groups, who are used to talking to distressed parents. They are working to convince parents of the value of donating a child's brain, should the child die in an accident. In parallel, the US National Institutes of Health (NIH) has signed up in principle to establish a nationwide network of brain collection that will actively include those of children, and serve wider biomedical communities.

Things are moving slowly, but at least they are moving. And it is not too early to think how this slow domestic progress could be geared up to an international scale. More countries means more donors, and the high natural variability between brains means that very large numbers can be needed to give studies of brain material statistical significance.

International networking of brain banks has been done before. BrainNet Europe, for example, was established 10 years ago as a single portal for brain tissue collected in 19 different European countries, none of which holds significant amounts of children's brains. The US advocacy organization Autism Speaks has already added a UK collection point in Oxford to its own brain bank.

\section{"It is understandable that bodies such as the NIH don't make strong public statements about extending fetal collections."}

Networked collections must also extend to fetal brains, and this is another reason for an international approach. At least eight people, including four doctors, associated with abortion procedures have been murdered for their activities in the United States in the past 20 years, so it is understandable that bodies such as the NIH don't make strong public statements about extending fetal collections.

The Lieber Institute for Brain Development in Baltimore, Maryland, dedicated to translational research in neurodevelopmental diseases, which opened formally this year, is building a collection of young brains to support its research programme. It will begin its fetal acquisitions at three locations in Europe - Scotland, Denmark and Bulgaria - where the political climate is less hostile. In fact, the Lieber institute is proving a model for how to move ahead on paediatric and fetal brain banking, with appropriate respect for personal and political sensitivities. Would it cooperate with a national or international brain bank network, if created? Yes, say its organizers. But it won't wait for it. There is too much important research that needs to be done.

\section{Animal talk}

\section{Germany must do more to encourage dialogue on animal experimentation.}

S andwiched between the towering edifices of the Bundestag and the Chancellor's office, and just a short walk from other government buildings, the old family villa that is home to the Swiss embassy makes for a curious sight in the political heart of modernday Berlin. Last week, the embassy hosted an international meeting of scientists from around the world who defend the use of animals in research. But despite being invited, nobody from the government offices bothered even to drop in. German animal-welfare groups also 